\title{
Multimodal Evoked Potential Studies in Leukodystrophies of Children
}

\author{
L.J. De Meirleir,* M.J. Taylor, W.J. Logan
}

\begin{abstract}
Evoked potentials were studied in 22 children with leukodystrophy [ 10 metachromatic leukodystrophy (MLD), 4 Pelizaeus-Merzbacher (PM), 3 Krabbes, 2 adrenoleukodystrophy (ALD), and one each of Alexander's, Canavan's and multiple sulphatase deficiency (MSD) diseases]. The ABRs were abnormal in all patients (except for the younger ALD), but varied with the type of leukodystrophy. The PM and Krabbes patients had abnormal ABRs with a loss of the rostral waves, accompanied in Krabbes with delayed I-III interpeak latencies; in MLD, ALD and MSD prolonged interpeak latencies were found. Three patients who had no clinical signs, but were positively diagnosed as MLD on the basis of absent arylsulphatase A, also had abnormal ABRs. The SEPs were abnormal in all patients. Cortical SEPs were absent in 16 and abnormal in 5 who were in the earlier stages of their disease. Cervical SEPs were within normal limits except for the Krabbes and MLD patients studied, who showed peripheral slowing. The VEPs were normal in only 6 and, unlike the ABRs and SEPs, did not seem to covary with clinical severity across the various leukodystrophies but did correlate with disease progression. Thus, multimodal EPs are useful in the diagnostic differentiation of the leukodystrophies.
\end{abstract}

\begin{abstract}
RÉSUMÉ: Etude des potentiels evoqués multimodes dans les leucodystrophies de l'enfant Nous avons étudié les potentiels évoqués chez22 enfants atteints de leucodystrophie [10étaient atteints de leucodystrophie métachromatique (LDM), 4 de maladie de Pelizaeus-Merzbacher (PM), 3 de maladie de Krabbes, 2 d'adrénoleucodystrophie (ALD) et 1 cas respectivement de maladie d'Alexander, de maladie de Canavan et de déficiences multiples en sulphatases (DMS)]. Les potenteils évoqués auditifs (PEA) étaient anormaux chez tous les patients (sauf chez le plus jeune ALD), mais variables selon le type de leucodystrophie. Les patients atteints de maladie de PM et de Krabbes avaient des PEA anormaux avec perte de l'onde rostrale, accompagnés d'un retard des latences interpics I-III chez les patients atteints de maladie de Krabbes: chez les patients atteints de LDM, d'ALD et de MSD, nous avons observé des latences interpics prolongées. Trois patients qui n'avaient pas de signes cliniques, mais avaient reçu un diagnostic de LDM basé sur une absence d'arylsulphatase A, avaient également des PEA anormaux. Les PES étaient anormaux chez tous les patients. Les PES corticaux étaient absents chez 16 patients et anormaux chez 5 autres qui étaient dans les premiers stages de leur maladie. Les PES étaient dans les limites de la normale sauf chez les patients atteints de maladie de Krabbes et de DMS, qui eux présentaient un ralentissement périphérique. Les PEV étaient normaux chez seulement 6 patients et, contrairement aux PEA et aux PES, ne semblaient pas varier en parallèle avec la sévérité de l'atteinte clinique dans les différentes leucodystrophies, mais manifestaient une corrélation avec la progression de la maladie. Il s'est donc avéré que les PES multimodes sont utiles dans la différentiation diagnostique des leucodystrophies.
\end{abstract}

Can. J. Neurol. Sci. 1988; 15:26-3I

The leukodystrophies are a group of inherited white matter degenerative diseases characterized by variable clinical presentation and age of onset. The usefulness of evoked potentials (EPs) in revealing early demyelinating processes is well known, and they can also aid in the differentiation between gray and white matter degenerative diseases. ${ }^{1,2}$ Multimodal evoked potentials (EPs) have been described in a number of leukodystrophy patients, ${ }^{3-6}$ mainly in Pelizaeus-Merzbacher and adrenoleukodystrophy. Also adrenoleukodystrophy carriers were reported to have abnormal EPs. ${ }^{8} 10$ However, a specific EP profile of the different leukodystrophies has not yet been established. Our study was to investigate multimodal EPs in the various leukodystrophies, and to determine their possible role as an aid in differential and early diagnosis.

\section{METHODS}

\section{Patients}

Twenty-two children with leukodystrophy were studied. Their ages are shown in Table 1 . These included 10 with metachromatic leukodystrophy (MLD), 4 with Pelizaeus-Merzbacher disease (PM), 3 with Krabbes disease, two with adrenoleukodystrophy (ALD) and one each with Alexander's disease, multiple sulphatase deficiency (MSD) and Canavan's disease.

The diagnoses of the MLD patients were all confirmed by absent arylsulfatase $A$ activity in enzymatic assays in fibroblasts and leukocytes. The patient with MSD had increased urinary sulfatides and severe deficiency of arylsulfatase $B$ and $\mathrm{C}$, at $15 \%$, and partial deficiency of arylsulfatase A with $30 \%$

From the Division of Neurology, Hospital for Sick Children, University of Toronto, Toronto

Received February 12, 1987. Accepted in final form July 12, 1987

*Current Address: AZ Kinderziekenhuis, Department of Pediatrics, Laarbeeklaan, 1090 Brussels, Belgium

Reprint requests to: Dr. M.J. Taylor, Division of Neurology, Hospital for Sick Children, 555 University Avenue, Toronto, Ontario M5J IX8 
Table 1: Diagnostic Categories and Ages

\begin{tabular}{llll}
\hline \hline Patients & Diagnosis & age(s) & EP Studies done \\
\hline PM* $^{*}$ & 17 months & ABR, VEP, ERG, SEP \\
PM* $^{*}$ & $16 \mathrm{~m} / 18 \mathrm{~m} / 2$ years & ABR, VEP, SEP \\
PM* $^{*}$ & 5 years & ABR, VEP, ERG, SEP \\
PM* $^{*}$ & 9 years & ABR, VEP, ERG, SEP \\
MLD $^{\circ}$ & 1.5 years & ABR \\
MLD & 2.5 years & ABR, VEP, ERG, SEP \\
MLD & 2.5 years/4 years & ABR, VEP, ERG, SEP \\
MLD & 2.5 years & ABR \\
MLD & 3 years & ABR, VEP, ERG, SEP \\
MLD & 3 years & ABR \\
MLD & 3 years & ABR \\
MLD & 4.5 years & ABR \\
MLD & 4.8 years & ABR, VEP, ERG \\
MLD & 7 years & ABR, VEP, ERG, SEP \\
Krabbes & 4.5 months & ABR, VEP, ERG, SEP \\
Krabbes & 6 months & ABR \\
Krabbes & 6 months $/ 10$ months & ABR, VEP, ERG, SEP \\
Canavan's* & 7 months $/ 4$ years & ABR, VEP, ERG, SEP \\
MSD & 6 years & ABR, VEP, ERG \\
Alexander's & 6 years & ABR, VEP, ERG, SEP \\
ALD & 8 years/9 years & ABR, VEP, ERG, SEP \\
ALD & 13 years/16 years & ABR, VEP, SEP \\
\hline
\end{tabular}

\section{ALD - adrenoleukodystrophy}

MLD - metachromatic leukodystrophy

MSD - multiple sulfatase deficiency

PM - Pelizaeus Merzbacher

* - clinical diagnosis

- - asymptomatic, enzymatically diagnosed

residual activity on cultured fibroblasts. The patients with Krabbes disease had increased CSF protein and deficiency of betagalactocerebrosidase in leukocytes and fibroblasts. The four patients with PM disease had typical clinical features consisting of nystagmus appearing in the first few months of life, slow development and later hyperreflexia, spasticity and optic atrophy. In two of the four PM patients an MRI study suggested abnormal white matter. Alexander's disease was diagnosed in a child with megalencephaly, severe motor and developmental deficit and the presence of Rosenthal fibres and demyelination on brain biopsy. The patient with Canavan's disease was clinically and radiologically diagnosed with megalencephaly, lack of psychomotor development and optic atrophy as main clinical findings and $\mathrm{CT}$ scan findings of increased lucency in the white matter without accentuation after contrast enhancement. Adrenoleukodystrophy was confirmed in both cases by a lack of response to ACTH, the presence of long chain fatty acids (C26) in urine and fibroblasts and a typical demyelination pattern on CT scan ${ }^{11}$ and MRI. ${ }^{12}$ Three patients in the MLD group were presymptomatic, but positively diagnosed siblings of clinically affected children.

\section{Procedure}

The EP studies completed on each patient are shown in Table 1. Auditory brainstem responses (ABRs) were recorded between $\mathrm{Cz}$ and ipsilateral earlobe in response to monaural rarefaction click stimuli (70-90 dBHL), with contralateral masking, presented at a rate of $11 / \mathrm{s}$. At least two averages of 1024 trials were averaged for each ear. The bandpass was $150-3000 \mathrm{~Hz}$, the gain was $100 \mathrm{k}$ and the sweep was $10 \mathrm{~ms}$.

Visual evoked potentials (VEPs) and electroretinograms (ERGs) were recorded in response to monocular flash stimula- tion (only the ALD patients were cooperative enough for pattern reversal VEPs). ERGs were recorded from infraorbital electrodes, VEPs from electrodes at $01,0 \mathrm{z}$ and 02 , all referenced to $\mathrm{Fz}$. At least two averages of 128 trials each were collected for each eye. The bandpass was $1-100 \mathrm{~Hz}$, the gain was $20 \mathrm{k}$ and the sweep was $250 \mathrm{~ms}$.

Somatosensory evoked potentials (SEPs) were recorded over cervical spine ( $\mathrm{Cv} 7)$ and contralateral post-central somatosensory cortex $\left(\mathrm{C}^{\prime}\right.$ and $\left.\mathrm{C}^{\prime}\right)$, referenced to $\mathrm{Fpz}$, in response to unilateral electrical stimulation at motor threshold over the median nerve at the wrist. At least two averages of 256 trials were recorded. The bandpass was $30-3000 \mathrm{~Hz}$, the sweep was $50 \mathrm{~ms}$ and the gain was $40 \mathrm{k}$.

Grass gold cup electrodes were used in all cases; the impedance was always below $3 \mathrm{k}$ ohms. Twelve of the children needed to be sedated with chloral hydrate for adequate $A B R$ and spinal SEP testing to be carried out; cortical EPs were recorded without sedation. All the EP data were compared to age-matched normative values established in the lab (in the case of SEPs, age and size matched normals were used); our upper limit of normal was always $2.5 \mathrm{~s}$.d. above the mean $(\mathrm{p}<.01)$.

\section{RESULTS}

\section{ABRs (Figure 1)}

ABRs were abnormal in all patients except the youngest ALD when he was first tested. The most marked abnormalities, with the loss of component waves, were seen in the early onset

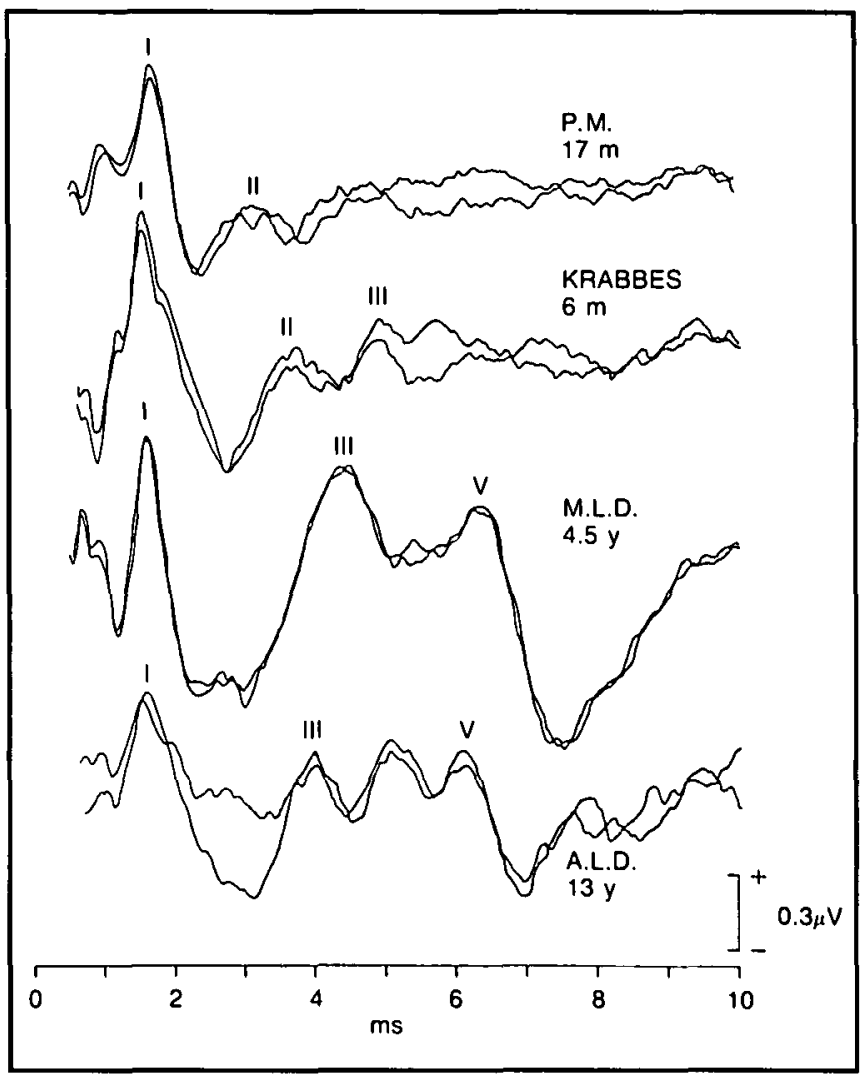

Figure I - ABRs in four leukodystrophy patients, showing the loss of the rostral waves in the PM and Krabbes patients (with prolongation of waves II and III in the Krabbes), and the delayed interpeak latencies in MLD and $A L D$, less marked in the latter. 


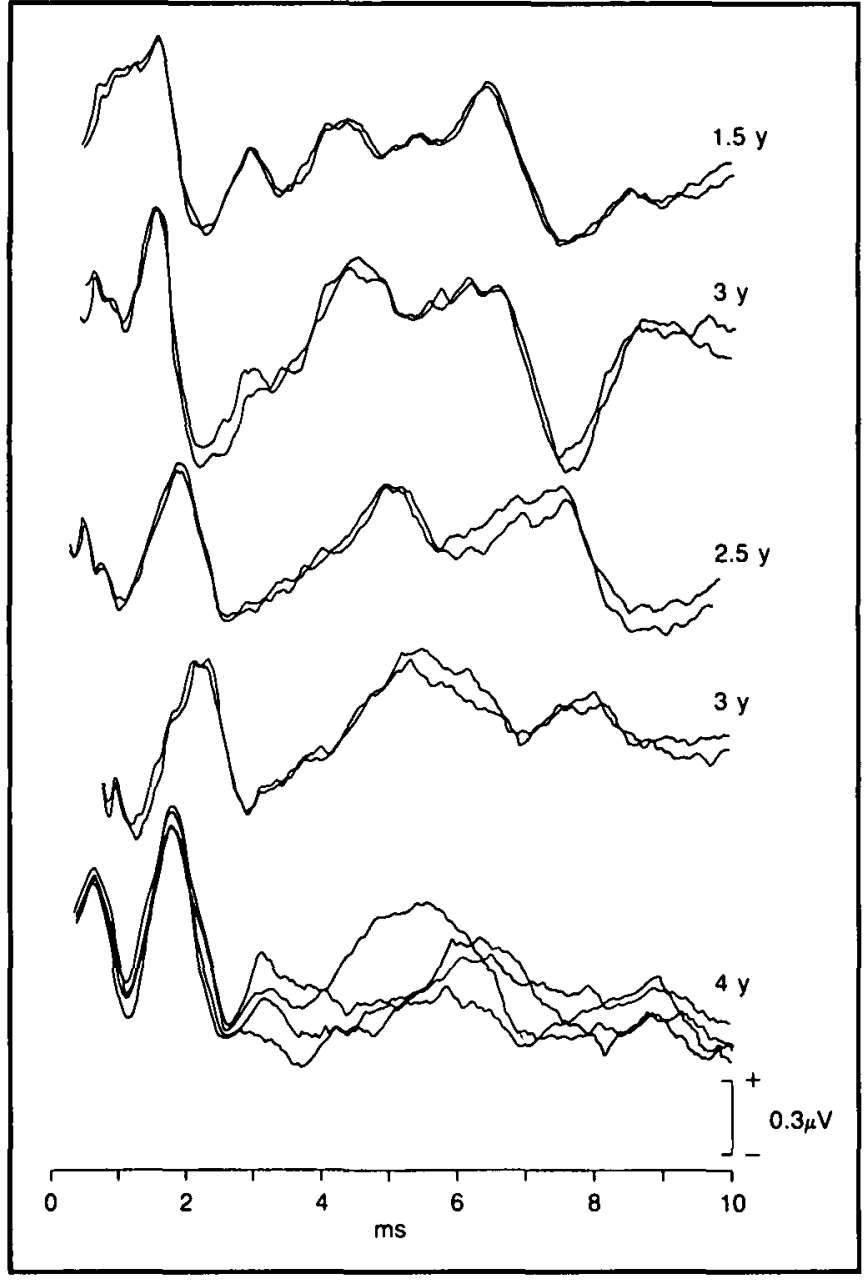

Figure $2-A B R$ s in five $M L D$ patients showing a deterioration in the waveform with disease severity. Initially, in the asymptomatic patients (top trace), only the I-III interpeak latencies are prolonged, with subsequent prolongation of the III-V as well and, finally, a loss of the later components.

leukodystrophies, Krabbes and PM. Two of the children with PM showed asymmetrical ABRs with loss of waves III-V on one side and poorly formed waves III- $\mathrm{V}$ with delayed latencies on the other side. In the oldest patient with PM only waves I-III were present bilaterally. The latencies of waves I and II were within normal limits in PM. In the Krabbes patients only waves I-III were present bilaterally, but with increased interpeak latencies. The MLD patients all had prolonged interpeak latencies, particularly between waves I and III. Interestingly, three presymptomatic children with confirmed MLD had abnormal ABRs with increased I-III and I-V latencies (Figure 2). Two older, more affected MLD patients had more pronounced abnormalities in their ABRs with very prolonged I-III latencies and the loss of waves IV and V (Figure 2). In one MLD family, normal ABRs were recorded in a sibling with normal arylsulfatase $A$ activity, and in both parents, in whom the arylsulfatase A was reduced.

A different pattern from the MLD population was found in the one patient with MSD, a variant of MLD, where the ABRs were normal on one side and just beyond normal limits on the other.

The patient with Canavan's disease when studied at 7 months of age had increased interpeak latencies, and when retested at 4

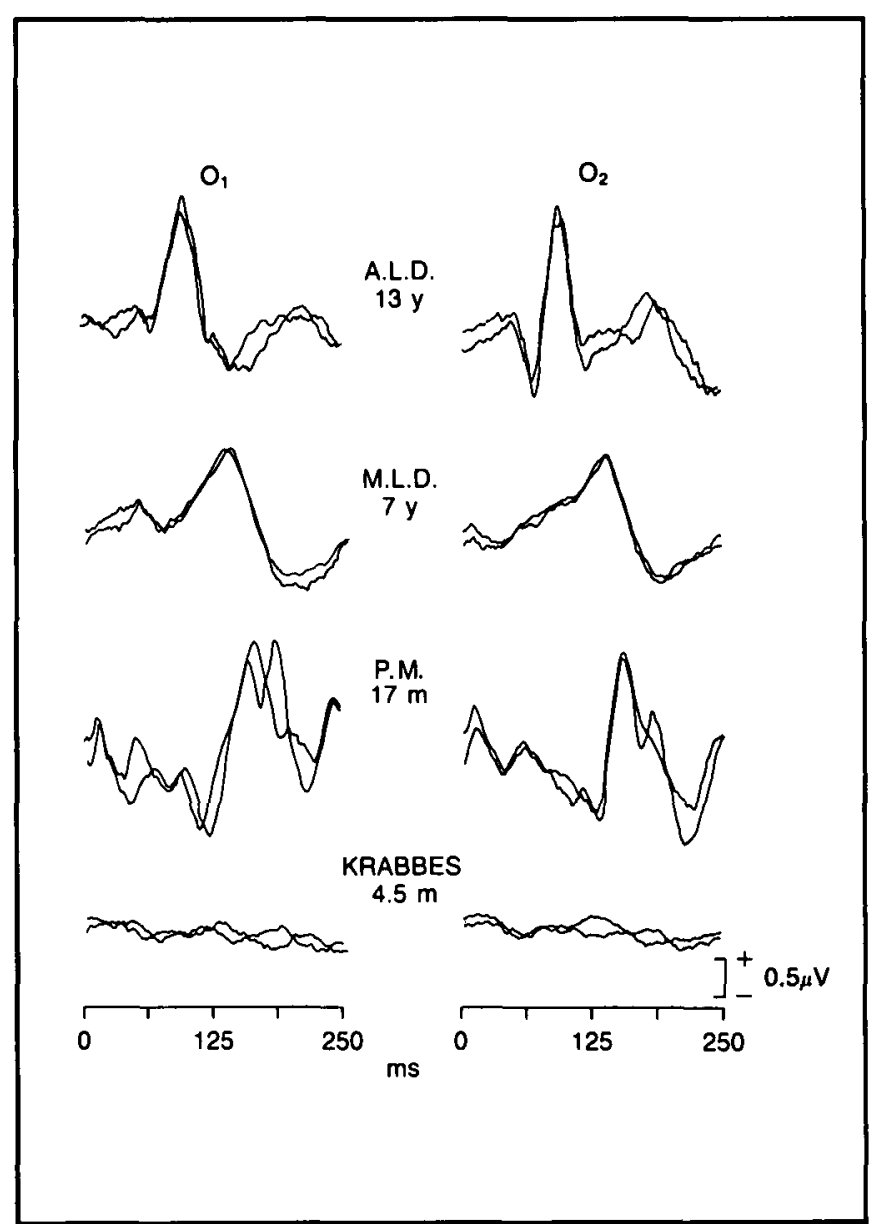

Figure 3 - VEPs in four leukodystrophy patients showing normal responses in the ALD, prolonged latencies of the P100 in MLD and PM and absent responses in Krabbes. Those with abnormal VEPs had normal ERGs.

years of age had only wave I present bilaterally. The child with Alexander's disease was 6 years of age and already in a vegetative state when studied; the ABRs showed prolonged interpeak latencies, and very poor wave, IV-V formation.

In the older boy with ALD, who had only mild neurological signs, only interpeak prolongation was found when he was tested both at 13 and 16 years of age. When the younger ALD patient was studied one year after he first presented he had marked neurological findings, had deteriorated rapidly and his ABRs showed increased interpeak latencies.

Wave I was present and within normal limits for all patients.

\section{VEPs (Figure 3)}

In three of the patients with PM the P100 to flash stimulation was delayed bilaterally; only in one of the younger patients ( 2 years old) were normal flash VEPs recorded. No recognizable VEPs could be recorded in the Krabbes or Canavan's patients. The VEPs were normal in the older boy with ALD when first studied, but he had very small amplitude, poorly formed VEPs on repeat testing three years later. The younger ALD patient had abnormally increased VEPs at 8 years of age, and absent waveforms with flash stimulation a year later. VEPs were normal in the cases of Alexander's and MSD. In the MLD group five patients had VEPs recorded; the 2.5 and 3 year olds had normal VEPs, while the 2 older patients (at 4.5 and 7 years) had delayed P100s, more marked in the latter. 


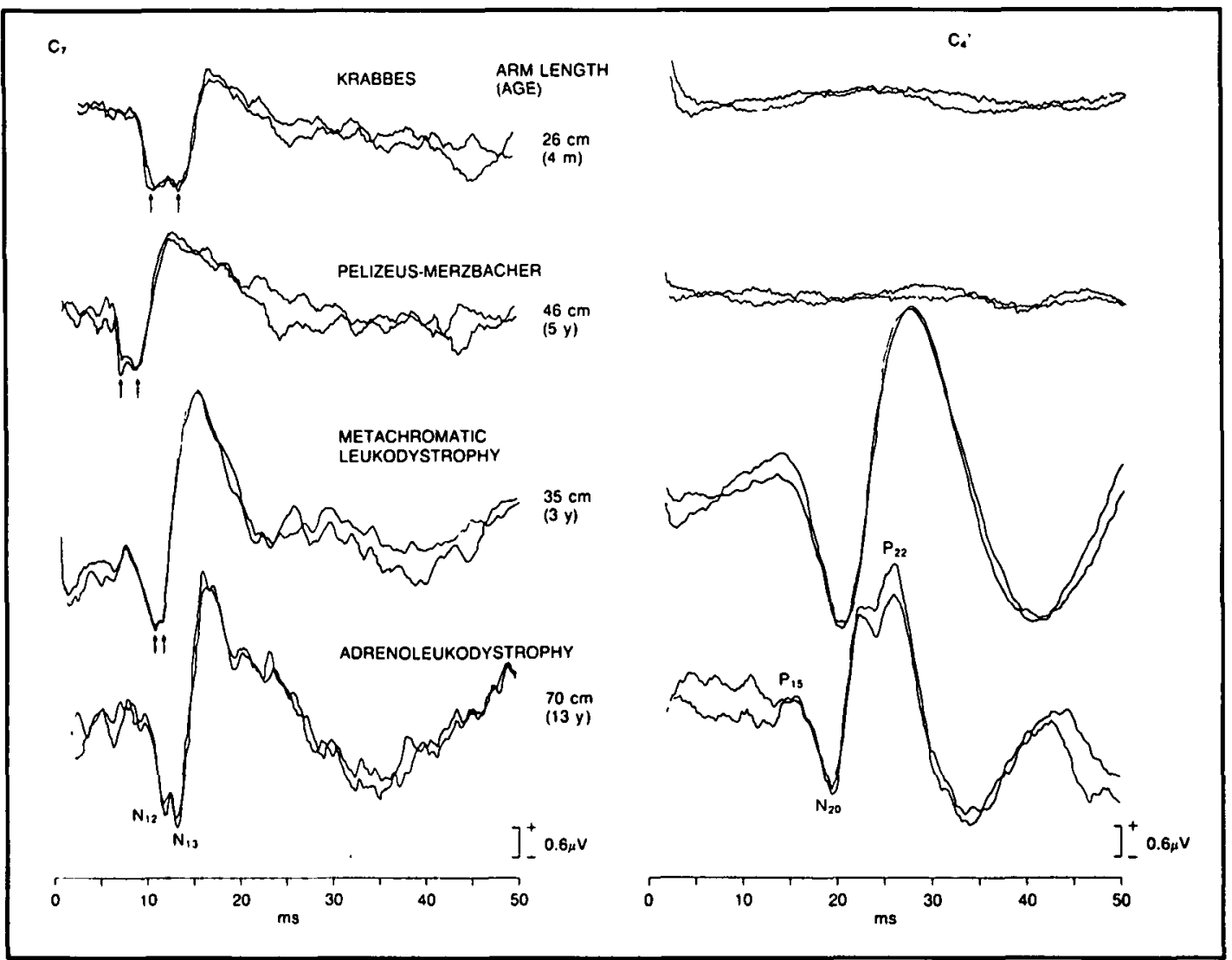

Figure 4-SEPs in four leukodystrophy patients, showing delayed peripheral responses (recorded from cervical spine C7) and absent cortical SEPs in Krabbes, normal peripheral but absent corticals in a $P M$ patient, delayed peripheral and cortical in both the MLD and ALD, but much more marked in the former (note differing arm lengths).

The ERGs were normal in all cases except the patient with MSD who showed only very small, bifid b-waves bilaterally.

\section{SEPs (Figure 4)}

SEPs were recorded in all the PM patients. Three had absent cortical responses and the fourth had delayed latencies. The peripheral responses were normal in two, but of increased latency in the oldest. In the two patients with Krabbes tested, no cortical responses and delayed peripheral conduction were seen.

The SEPs seemed to vary with age in the MLD patients studied. The three youngest had increased peripheral and central conduction but it was more marked in the 4 year old; the 2.5 year old, who was still asymptomatic, had latencies just above the upper limits of normal for his age and size. The eldest studied ( 8 years) had absent cortical responses.

The SEPs were abnormal in both patients with ALD, with normal peripheral conduction, increased central conduction times and asymmetrical cortical responses. The SEPs deteriorated with the repeat studies in these two boys, far more markedly in the younger patient, reflecting his clinical status. In the Canavan's and Alexander's patients, the cortical responses were absent while peripheral conduction was within normal range. The patient with Alexander's disease had only the N12 component in the cervical response, the $\mathrm{N} 13$ (the first postsynaptic component) was absent, indicating dorsal horn/cuneate nucleus involvement. ${ }^{13}$ This was the only patient in which this finding was noted. Nerve conduction studies were done in 13 of these patients and the findings were consistent in all cases with the results from the peripheral SEPs.

Repeat EP studies were done in six patients and showed deterioration with disease progression. This was most marked

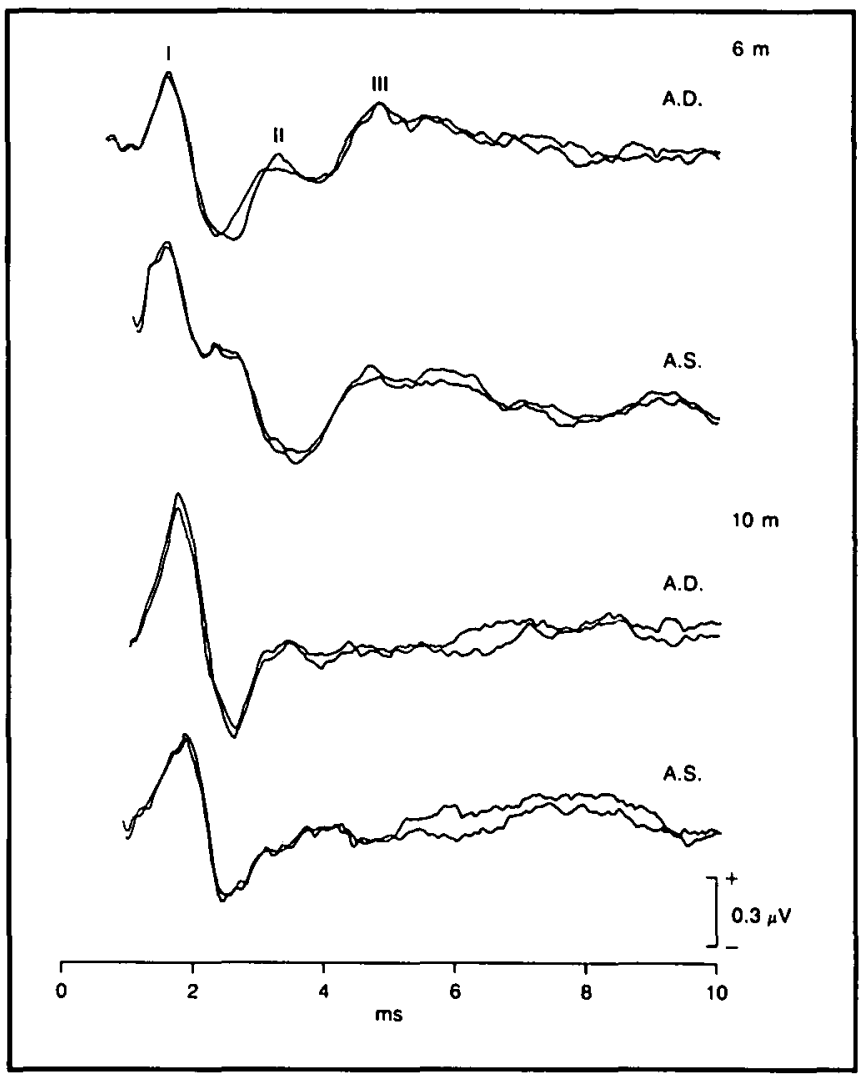

Figure 5-Repeat ABRs in a patient with Krabbes disease. At 6 months, only waves I, II and III could be easily identified (with prolonged I-III interpeak latencies). At 10 months, only wave I and a questionable wave II could be seen bilaterally. 
Table 2: EP Results for the Various Leukodystrophies

\begin{tabular}{|c|c|c|c|c|c|c|}
\hline & \multicolumn{2}{|c|}{ ABR } & \multicolumn{2}{|c|}{ VEP } & $\begin{array}{c}\text { periph } \\
\text { SEP }\end{array}$ & $\begin{array}{c}\text { central } \\
\text { SEP }\end{array}$ \\
\hline & & a. & & a. & e. a. & e. a. \\
\hline $\begin{array}{l}\text { PM } \\
\text { Krabbes } \\
\text { MLD } \\
\text { ALD } \\
\text { Canavan } \\
\text { Alexander } \\
\text { MSD }\end{array}$ & $\begin{array}{l}M \\
M \\
L \\
N / L \\
L \\
L\end{array}$ & $\begin{array}{l}\mathbf{M} \\
\mathbf{M} \\
\mathrm{M} \\
\mathrm{L} \\
\mathrm{M} \\
\mathbf{M}\end{array}$ & $\begin{array}{l}\mathrm{L} \\
\mathrm{A} \\
\mathrm{N} \\
\mathrm{N} / \mathrm{L} \\
\mathrm{A} \\
\mathrm{N}\end{array}$ & $\begin{array}{l}\text { L } \\
\text { M } \\
\text { A } \\
\text { N }\end{array}$ & $\begin{array}{ll}\mathbf{N} & \mathbf{N} \\
\mathbf{L} & \mathbf{M} \\
\mathbf{L} & \mathrm{L} \\
\mathbf{N} & \\
& \mathbf{N} \\
& \mathbf{M}\end{array}$ & $\begin{array}{ll}\text { M } & \text { A } \\
\text { A } & \text { A } \\
\text { L } & \text { A } \\
\text { L } & \text { L }+ \text { M } \\
& \text { A } \\
& \text { A }\end{array}$ \\
\hline
\end{tabular}

e. - early disease

a. - advanced disease

$\mathrm{N}$ - normal

L - $\uparrow$ interpeak latencies

$\mathrm{M}$ - missing waveforms

A - absent

in the infantile onset leukodystrophies (i.e., Krabbes, PM) where the ABRs could show degeneration in as little as 4 months (Figure 5), but a worsening of the EPs was also seen over longer periods in ALD and MLD patients.

\section{Discussion}

The largest group studied were the MLD patients including eight with late infantile and two considered to be juvenile MLD. Evoked potentials in this disease provide useful information. ABRs are perhaps the most sensitive, showing typical abnormalities even in the three presymptomatic patients with late infantile MLD indicating the early and profound brainstem demyelination typical of MLD. This is in contrast to what Lütschg $(1984)^{7}$ found with a presymptomatic patient with juvenile MLD. Progression of the disease, based on the crosssectional data, is characterized by increasing abnormalities of the ABRs; there were further increases in interpeak latencies and subsequent loss of later waves signifying progressive demyelination of the pontomesencephalic regions of the brainstem. VEPs also reflected disease progression in these patients, becoming abnormal with prolonged latencies in later stages of the disorder. SEPs were abnormal very early and worsened with disease progression, but unfortunately only four MLD patients had SEP studies. We found that peripheral involvement was not evident across modalities at the time of diagnosis of MLD, when there is already widespread demyelination in the central nervous system. In none of the patients that we studied was a prolonged wave I seen in the ABRs, which would indicate involvement of the VIIIth nerve, even though this was described as typical of MLD by Markand et al. ${ }^{6}$ The ABRs in our two patients with juvenile MLD showed delayed central conduction even at high intensity levels, as found by Carlin et $\mathrm{al}^{14}$ but not by other investigators. ${ }^{4}$ In the one MLD family we studied, the normal sibling had both normal ABRs and normal arylsulfatase A activity, while the parents had decreased arylsulfatase A (in the carrier range) yet normal ABRs. This suggests that the ABRs are not reliable in detecting carriers of MLD.

In the early onset leukodystrophies (PM and Krabbes) the EPs were strikingly abnormal but the pattern of abnormality was different in the two disorders. Only the Krabbes patients showed peripheral slowing in both the ABRs and SEPs, the VEPs were present but delayed in PM, and absent in the Krabbes patients. The ABR and SEP abnormalities in PM are consistent with other reports. ${ }^{5,6,15,16}$ Although the ten patients with PM studied by Markand et al $^{6}$ had absent VEPs, all were older than any of the patients in our series. One report by Garg et $\mathrm{al}^{5}$ showed, however, very abnormal ABRs with the presence of only waves $I$ and II, in a one-month old baby with PM. Thus ABRs should be useful in the assessment of nystagmus in infancy, one the earliest manifestations of PM.

In the younger patient with biochemically confirmed ALD the ABRs were still normal at the time of the first investigation. This patient presented, however, with adrenal insufficiency and behavioural changes. A CT scan showed the posterior demyelination, typically seen in early ALD. When studied a year later, he had marked neurological symptoms, and all his EPs had deteriorated. Our older patient with ALD had mild neurological signs when first tested as reflected by his EPs; he had normal VEPs but increased interpeak latencies in the ABRs and SEPs; the latter also showed asymmetric cortical responses. These findings showed progression when he was retested, especially in his VEPs, and his clinical condition had also worsened. This is in accord with other studies where deterioration of the EPs correlated with disease progression. ${ }^{3,9,17}$ Several studies have reported that ALD carriers also have abnormal SEPs and/or ABRs, with the suggestion that EPs may be a sensitive means of detecting carriers. ${ }^{8-10,18}$ In accordance with this finding, the mothers of our ALD patients (confirmed as a carriers by analysis of long chain fatty acids) both had abnormal SEPs, one had abnormal ABRs, with normal VEPs.

Evoked potentials in a patient with MSD have not been reported to our knowledge. The abnormalities we found (abnormal ERGs, normal VEPs and only moderate increase in ABR interpeak latencies) differ from the EP findings in the MLD population. The ERG abnormalities are more consistent with the retinal degenerations seen in mucolipidosis and ceroid lipofuscinoses. The less severe abnormalities of the ABRs could reflect the residual activity of the arylsulfatase $A$, but more extensive studies of these patients and MLD carriers with reduced enzymatic activity need to be done.

In Canavan's disease the earliest sign of central demyelination were the absent VEPs and the increased interpeak latencies in the ABR. In contrast with Alexander's disease, optic atrophy is an early and major sign in Canavan's. When the patient was investigated at a more advanced stage of the disease, the ABRs showed a loss of all components after wave $I$ and no cortical SEPs could be recorded. Since Canavan's and Alexander's disease can be difficult to distinguish clinically, the VEPs may be useful, as they were still within normal limits in the advanced Alexander's patient but absent early in Canavan's. In Alexander's disease the marked demyelination has a frontal predominance, with a frontal to occipital gradient; cerebral degeneration is extensive ${ }^{19}$ Peripheral myelin is usually spared, ${ }^{20}$ reflected by the normal peripheral SEP component (N12), but gray and white matter of the spinal cord are affected, perhaps accounting for the absent spinal component (N13).

\section{Conclusions}

The leukodystrophies are a heterogeneous group, characterized by CNS demyelination and sometimes peripheral involvement. Although metabolic, neuroradiological and pathological investigations have become more informative in these diseases, evoked potentials may be a useful tool in early detection and in 
differentiating these disorders when other tests are inconclusive. From the current data ABRs appear the most valuable of the EPs as they are abnormal in all leukodystrophy patients (with the single exception of the presymptomatic ALD patient) and the pattern varies with the type of leukodystrophy. The SEPs, VEPs and ERGs provide additional diagnostic specificity as their profile of abnormalities is different in the various leukodystrophies. The present data suggest that multimodal evoked potential studies can help in differentiating the leukodystrophies and should aid our understanding of their pathogenesis and natural history.

\section{REFERENCES}

1. Hecox KE. Brainstem auditory evoked responses in the diagnosis of pediatric diseases. Neurology 1981; 31: 832-845.

2. Stockard JJ, Stockard JE, Sharbrough FW. Brainstem auditory evoked potentials in neurology: Methodology, interpretation, clinical application. I $n$ : Aminoff MJ, ed. Electrodiagnosis in Clinical Neurology. Churchill Livingstone, New York 1980: 370-413.

3. Black JA, Fareillo RG, Chun RW. Brainstem auditory evoked response in adrenoleukodystrophy. Ann Neurol 1979;6:269-270.

4. Brown FR, Shimizu H, McDonald JM, et al. Auditory evoked brainstem response and high-performance liquid chromatography sulfatide assay as early indices of metachromatic leukodystrophy. Neurology 1981; 31: 980-985.

5. Garg BP, Markand ON, DeMyer WE. Usefulness of BAER studies in the early diagonsis of Pelizaeus-Merzbacher disease. Neurology 1983; 33: 955-956.

6. Markand ON, Garg BP, DeMyer WE, et al. Brain stem auditory, visual and somatosensory evoked potentials in leukodystrophies. Electroenceph Clin Neurophysiol 1982; 54: 39-48.

7. Lütschg J. Pathophysiological aspects of central and peripheral myelin lesions. Neuropediatrics 1984; 15 (supp.) 24-27.
8. Moloney JBM, Masterson JG. Detection of adrenoleukodystrophy carriers by means of evoked potentials. Lancet $1982 ; 2: 852-853$.

9. Garg BP, Markand ON, DeMyer WE, et al. Evoked response studies in patients with adrenoleukodystrophy and heterozygous relatives. Arch Neurol 1983; 40: 356-359.

10. Tobimatsu S, Fukui R, Kato M et al. Multimodality evoked potentials in patients and carriers with adrenoleukodystrophy and adrenomyeloneuropathy. Electroenceph Clin Neurophysiol 1985; 62: $18-24$

11. Aubourg P, Diebler C. Adrenoleukodystrophy. Its diverse CT appearances and an evolutive or phenotype variant. Neurorad 1982; 24: 33-42.

12. Young RS, Osbarren MD, Aleer PM, Ramer JC, Weidner WA, Daie JD. Magnetic resonance imaging in leukodystrophies of childhood. Ped Neurol 1985; 1: 15-19.

13. Taylor MJ, Borrett DS, Coles JC. The effects of profound hypothermia on the cervical SEP in humans: Evidence of dual generators. Electroenceph Clin Neurophysiol 1985; 62: 184-192.

14. Carlin L, Roach SE, Riela A, Spudis E, McLean WT. Juvenile metachromatic leukodystrophy: Evoked potentials and computed tomography. Ann Neurol 1983; 13: 105-106.

15. Ochs R, Markand ON, DeMyer WE. Brainstem auditory evoked responses in leukodystrophies. Neurology 1979;29: 1089-1093.

16. Wilkus RJ, Farrell DF. Electrophysiologic observations in the classical form of Pelizaeus-Merzbacher disease. Neurology 1976; 26: $1042-1045$.

17. Kaga K, Tokoro Y, Tanaka Y. The progress of adrenoleukodystrophy as revealed by auditory brainstem evoked responses and brainstem histology. Arch Otorhinolaryngol 1980; 228: 17-27.

18. Mamoli B, Graf M, Toifl K. EEG, pattern-evoked potentials and nerve conduction velocity in a family with adrenoleukodystrophy. Electroenceph Clin Neurophysiol 1979; 47: 411-419.

19. Borrett D, Becker LE. Alexander's disease. A disease of astrocytes. Brain 1985; 108: 367-385.

20. Becker LE, Yates A. Inherited metabolic disease. In: Textbook of Neuropathology, Davis RL, Robertson DM, eds. Williams \& Wilkin Baltimore, 1985; pp. 